\title{
Evaluation of Marginal Adaptation and Microleakage of Three Glass Ionomer-Based Class V Restorations: In Vitro Study
}

\author{
Maha M. Ebaya ${ }^{1} \quad$ Ashraf I. Ali ${ }^{1} \quad$ Salah H. Mahmoud ${ }^{1}$ \\ 1Department of Operative Dentistry, Faculty of Dentistry, Mansoura \\ University, Mansoura, Egypt
}

Address for correspondence Salah $\mathrm{H}$. Mahmoud, BDS, MDS, PhD, Department of Operative Dentistry, Faculty of Dentistry, Mansoura University, Algomhoria Street, Mansoura, Aldakhlia, Egypt P.O. (box) 35516 (e-mail: Salahmahmoud2010@yahoo.com).

Eur J Dent 2019;13:599-606

\begin{abstract}
Keywords

- glass ionomer

- scanning electron microscopy

- resin-modified glass ionomer

- microleakage

Objective The aim of this study was to evaluate and compare the marginal adaptation and microleakage of class $\mathrm{V}$ cavities restored with conventional glass ionomer cement $(\mathrm{GIC})$, resin-modified glass ionomer (RMGI), and bioactive ionic resin (BIR) restorative materials after 6 months of water storage.

Materials and Methods One hundred twenty standardized class $V$ cavities ( $2 \mathrm{~mm}$ deep, $4 \mathrm{~mm}$ in width, and $3 \mathrm{~mm}$ in height) were prepared in sound extracted human molar teeth, where the coronal margins were in enamel while the cervical margins were in dentin. Three glass ionomer-based restorations were tested $(n=40)$ : GIC (Equia Fil), RMGI (Fuji II LC), and BIR (ACTIVA Bioactive Restorative). Half of the teeth from each group $(n=20)$ were evaluated for their marginal adaptation with scanning electron microscopy and the other half submitted to dye penetration test to examine microleakage. Further division for each subgroup $(n=10)$ occurred to be tested immediately, while the remaining teeth were examined after keeping for 6 months and thermocycling.

Statistical analysis The outcomes were analyzed by Kruskal-Wallis and MannWhitney $U$ tests.

Results No statistically significant differences were observed among the three studied restorative materials. However, the differences were statistically significant in microleakage test between enamel and dentin and after water aging.

Conclusion All tested restorative materials exhibited the same marginal adaptation and microleakage. Dentin substrate revealed greater microleakage than enamel, especially with BIR restorative material. Water aging had a negative effect on RMGI with respect to microleakage.
\end{abstract}

\section{Introduction}

Over the past decades, a great progress occurred in esthetic dentistry, resulting in the evolution of a lot of restorative materials with magnificent improvement. Presently, these materials performance take up the main concern regarding the marginal sealing integrity and their durability, especially in that cavities that involve the cementum region, where clinical problems are aggravated. ${ }^{1}$
Marginal adaptation is the interfacial distance among the restoration and the tooth structure. The better sealing for the margins, the lesser microleakage occurs, furthermore secondary caries, and postoperative sensitivity will be reduced. Using fluoride-releasing materials and good bonding agent enhance good marginal adaptation; due to the crystalline deposits resulting from the fluoride-releasing materials, the formed crystals shape and quality differed with the material. ${ }^{2}$ 
Glass ionomer (GI) restoratives offer reasonable esthetics and durability, chemical bonding, fluoride release, and caries inhibiting potentials without extensive sound tooth structure preparation. ${ }^{3}$ Many types and modifications have been advanced with additives to enhance the materials mechanical and esthetic characteristics. ${ }^{4}$ Resin-modified glass ionomers (RMGIs) are one of these modifications. In these materials, a second resin polymerization reaction is supplemented to the fundamental acid-base reaction takes place. RMGI materials require easier clinical procedures and have better mechanical strength and esthetics. ${ }^{5}$

Bioactive restorative materials have been developed as a result of continuous evolution in material sciences. The addition of bioactive glass to glass ionomer cement (GIC) structure enhances bioactivity, reconstruction, and regeneration capacity of the tooth. ACTIVA products are composed of an enhanced RMGI with a blend of diurethane monomers modulated by incorporation of methacrylate-based monomers and a hydrogenated polybutadiene (a synthetic rubber). The added resin monomers are claimed to improve wear resistance and marginal chipping. These products include bioactive fillers, which simulate the natural teeth chemical and physical characteristics. They actively participate in the ion exchange dynamic system between the tooth structure and saliva. In addition, calcium, phosphate, and more fluoride can be released and recharged than that with GIC and continuously react to $\mathrm{pH}$ changes in the mouth. They can also make a chemical bond to tooth structure that leads to sealing of the cavity margins and prevention of bacterial microleakage. As a result of the distinctive bioactive dental materials characteristic, they are claimed to minimize gap formation at the tooth-restoration interface and microleakage. ${ }^{6}$

According to the mentioned above, the comparison of novel bioactive material with GIC and RMGI will allow practitioners to achieve clinical decisions with informed evidence-based, and foresee the restorative materials prognosis. Moreover, in vitro thermocycling allows the tested restorative materials to simulate the oral environment. The indexed literature has shown that there are limited studies that have assessed and compared marginal adaptation and microleakage of these restorations. Therefore, a comparative study between GIC, RMGI, and BIR in the presence of thermocycling was performed and hypothesized that there would be no differences among them.

\section{Materials and Methods}

Materials tested in the current study include GIC (EQUIA Fil), RMGI (Fuji II LC), BIR (ACTIVA), and the full description of the materials is illustrated in - Table $\mathbf{1}$.

\section{Methods}

\section{Teeth Selection}

One hundred twenty freshly extracted maxillary and mandibular third molars of similar size were selected for this study from the Oral Surgery Clinic, Faculty of Dentistry, Mansoura University after obtaining ethical approval. Patients' age ranged from 17 to 30 years. All teeth were examined macroscopically and microscopically (20× magnification) to rule out the presence of fractures, fissures, carious lesions, abrasive or erosion lesions, and restorations. Soft tissue remnants were removed using hand scaler (Zeffiro; Lascod, Florence, Italy); then teeth were disinfected with $1 \%$ chloramine-T solution, and subsequently kept for 24 hours at $37^{\circ} \mathrm{C}$ distilled water in an incubator (BTC, Model: BT1020, Cairo, Egypt).

\section{Cavity Preparation}

On the buccal surfaces of each tooth, standardized rectangular class $\mathrm{V}$ conventional cavities with 90 degrees cavosurface angles without bevel designs were prepared using carbide burs No. 271 at high speed with air/water coolant (W\&H, SN 0012845); each bur was used to prepare five cavities${ }^{6}$ the preparation dimensions were measured $2 \mathrm{~mm}$ depth, $4 \mathrm{~mm}$ mesiodistal width, and $3 \mathrm{~mm}$ occlusogingival height with enamel occlusal margins, while the cervical margins were located in dentin, all margins were prepared with 90 degree cavosurface angles without bevel. The dimensions

Table 1 Materials used in the study

\begin{tabular}{|l|l|l|l|l|}
\hline Manufacturer & Patch number & Composition & Type and reaction & $\begin{array}{l}\text { Restorative } \\
\text { material }\end{array}$ \\
\hline $\begin{array}{l}\text { GC Corporation, } \\
\text { Tokyo, Japan }\end{array}$ & 1602201 & $\begin{array}{l}\text { Powder: 95\% strontium fluoroalumino silicate } \\
\text { (FAS) glass } \\
\text { Powder: 5\% polyacrylic acid } \\
\text { Liquid: 40\% aqueous poly acrylic acid liquid }\end{array}$ & $\begin{array}{l}\text { Conventional glass } \\
\text { ionomer (chemical) }\end{array}$ & EQUIA Fil \\
\hline $\begin{array}{l}\text { GC Corporation } \\
\text { Tokyo, Japan }\end{array}$ & 1604218 & $\begin{array}{l}\text { Powder: FAS } \\
\text { Liquid: polyacrylic acid (20-25\%), 2-hydroxyle- } \\
\text { thyl methacrylate bicarbonate (1-5\%), proprie- } \\
\text { tary ingredient (5-15\%) }\end{array}$ & $\begin{array}{l}\text { Resin-modified glass } \\
\text { ionomer (dual-cure) }\end{array}$ & GC Fuji II LC \\
\hline $\begin{array}{l}\text { Pulpdent; } \\
\text { Watertown, } \\
\begin{array}{l}\text { Massachusetts, } \\
\text { United States }\end{array}\end{array}$ & $\begin{array}{l}\text { Powder: diurethane dimethacrylate, bis } \\
\text { (2-(methacryloyloxy) ethyl) } \\
\text { Phosphate, barium glass, ionomer glass, sodium } \\
\text { fluoride, colorants } \\
\text { Liquid: polyacrylic acid/maleic acid copolymer }\end{array}$ & $\begin{array}{l}\text { Bioactive resin } \\
\text { matrix and bioactive } \\
\text { glass fillers (du-cure chemistry) }\end{array}$ & $\begin{array}{l}\text { ACTIVA BIOACTIVE } \\
\text { RESTORATIVE }\end{array}$ \\
\hline $\begin{array}{l}\text { GC Corporation, } \\
\text { Tokyo, Japan }\end{array}$ & 150360 & $\begin{array}{l}\text { 50\% methyl methacrylate, 0.09\% camphorqui- } \\
\text { none }\end{array}$ & $\begin{array}{l}\text { Low-viscosity na- } \\
\text { no-filled resin coat }\end{array}$ & $\begin{array}{l}\text { G-Coat Plus } \\
\text { Low-viscosity na- } \\
\text { no-filled resin coat }\end{array}$ \\
\hline
\end{tabular}


were measured using a digital caliper for the length and the width, were drawn with an inerasable pen, and cavities were prepared inside it. However, the depth of the cavity was controlled during preparation with stopper in the bur and regularly checked with a marked periodontal probe. ${ }^{7}$

\section{Restorative Procedures and Study Groups}

The selected teeth were assigned randomly into three main groups $(n=40)$ : group 1 was restored with GIC (Equia Fil), group 2 was restored with RMGI (Fuji II LC), and group 3 was restored with BIR (ACTIVA Bioactive Restorative) according to the instructions of manufacturer.

RMGI and BIR, respectively, were cured with an LED curing light according to the manufacturers' instructions (Bluephase; Ivoclar Vivadent). Each specimen's surface was oriented perpendicular to the curing light at a distance less than or equal to $1.0 \mathrm{~mm}$. The light curing intensity was measured and monitored with a radiometer (Bluephase Meter, Ivoclar Vivadent) at $800 \mathrm{~mW} / \mathrm{cm}^{2}$. For both materials, the surface of each specimen was exposed to curing light for 40 seconds. For the GIC and RMGI restorations, G-Coat Plus was applied on both surfaces using a micro-brush and photo cured for 20 seconds. For all materials, specimens were stored prior to the finishing and polishing procedures in an incubator (BTC, Model: BT1020, Egypt) for 24 hours at $37^{\circ} \mathrm{C}$ distilled water. To reduce variability, all teeth preparations were performed by the same operator.

Each group was further assigned into two subgroups $(n=$ 20): subgroup (a) was subjected to the marginal adaptation evaluation, while subgroup (b) was subjected to the microleakage test.

\section{Artificial Aging}

Half of the teeth of each subgroup ( $n=10)$ were kept in $37^{\circ} \mathrm{C}$ distilled water for 6 months in an incubator. After keeping, teeth were undergone an alternating thermal cycle $(5,000$ cycles, $5-55^{\circ} \mathrm{C}$ ) between water paths with a 15 -second dwell time for each bath (SD Mechatronik Thermocycler, Germany). To produce a reliable thermocycling effect, continuous checking for water temperature had occurred.?

\section{Marginal Adaptation Evaluation by SEM}

The specimens for each group were dehydrated, mounted on aluminum stubs, and then gold sputter coated. Scanning electron microscopy (SEM) (LEO VP 435 [Carl-Zeiss NTS Gmbh; Oberochen, Germany]) was then used to assess the marginal adaptation of enamel and dentin margins at $200 \times$ magnifications. The margins were scored based on the following criteria8:

1. No marginal gap

2. Maximum marginal gap not exceeds $30 \mu \mathrm{m}$

3. Maximum marginal gap exceeds $30 \mu \mathrm{m}$

\section{Microleakage Assessment}

All tooth surfaces were painted with nail varnish and modeling wax, leaving $1 \mathrm{~mm}$ away from cavity margin. The teeth were immersed in $2 \%$ methylene blue dye for 24 hours at room temperature, and then removed from the solution, and rinsed for 30 seconds with distilled water. Buccolingual sections of $1 \mathrm{~mm}$-thickness were made for each specimen and standardized using a metal gauge. To maintain an even plane for each section, a slow-speed diamond microsaw was used for cutting (Buehler Ltd., Lake Bluff, Illinois United States). ${ }^{9}$ The sections were evaluated with a stereomicroscope at $40 \times$ (MA 100 Nikon Stereomicroscope, Japan) to determine the dye penetration extension at the margins of enamel and dentin. A single observer measured the degree of microleakage using the following scoring criteria, ${ }^{10}$

1. Negative dye penetration

2. Dye penetration not surpassing the middle of the cavity depth

3. Dye penetration exceed the middle of the cavity depth

4. Dye penetration extends over the axial wall

\section{Results}

Statistical Package for Social Science software program version 23 (SPSS, Inc., Chicago, Illinois, United States) was used to anatomize the data. Interquartile range and median were used for representation of the data as the. The Kruskal-Wallis test was applied to differentiate between more than two various groups of nonparametric data, while the Mann-Whitney $U$ test was applied to confront between nonparametric data of two various groups. A $p$-value $<0.05$ was deemed statistically significant.

\section{Marginal Adaptation Evaluation Results}

The outcomes of Kruskal-Wallis test exhibited no significant difference between all the studied restorative materials both in enamel and dentin or immediately and after aging; moreover, the Mann-Whitney $U$ test manifested nonsignificant differences for each material immediately and after artificial aging within enamel and dentin. These outcomes are represented in - Table $\mathbf{2}$ and $\boldsymbol{- F i g s .} \mathbf{1}$ and $\mathbf{2}$.

\section{Microleakage Test Results}

The Kruskal-Wallis test exhibited no significant difference between the three studied restorative materials both in enamel and dentin in immediate and delayed results with probability values greater than 0.05 ; also, the Mann-Whitney $U$ test demonstrated that GIC and BIR didn't significantly differ either immediately or after artificial aging in enamel and dentin. However, the differences were statistically significant in RMGI regarding aging; moreover, Mann-Whitney $U$ test manifested insignificant difference among enamel and dentin either immediately or after aging with GIC and RMGI $(p>0.05)$. While in BIR restorative material, there was significant difference. These outcomes are presented in -Table 3 and - Fig. 3.

\section{Discussion}

An absolutely perfect marginal seal is not realizable, but a good marginal quality for the longevity of the restoration 
Table 2 Comparison of marginal adaptation among different types of restoration according to time and site

\begin{tabular}{|l|l|l|l|l|}
\hline \multirow{2}{*}{\multicolumn{2}{c|}{}} & \multicolumn{2}{c|}{ Restoration } \\
\cline { 3 - 5 } \multicolumn{2}{|c|}{ Immediate } & GIC & RMGI & BIR \\
\cline { 2 - 5 } & Enamel & $0.00(0.00-0.00)^{\mathrm{Aa}}$ & $0.00(0.00-0.00)^{\mathrm{Aa}}$ & $0.00(0.00-0.00)^{\mathrm{Aa}}$ \\
\cline { 2 - 5 } & Dentin & $0.00(0.00-1.00)^{\mathrm{Aa}}$ & $0.00(0.00-0.00)^{\mathrm{Aa}}$ & $0.00(0.00-0.00)^{\mathrm{Aa}}$ \\
\hline \multirow{2}{*}{ Delayed } & Enamel & $0.00(0.00-1.00)^{\mathrm{Aa}}$ & $0.00(0.00-1.00)^{\mathrm{Aa}}$ & $0.00(0.00-0.00)^{\mathrm{Aa}}$ \\
\cline { 2 - 5 } & Dentin & $1.00(0.00-1.00)^{\mathrm{Aa}}$ & $0.50(0.00-1.00)^{\mathrm{Aa}}$ & $0.00(0.00-0.00)^{\mathrm{Aa}}$ \\
\hline
\end{tabular}

Abbreviations: BIR, bioactive ionic resin; GIC, glass ionomer cement; RMGI, resin-modified glass ionomer.

Note: Data are expressed as median (IQR), IQR: interquartile range. Significance < 0.05 . Different letters represent significant differences. Capital letters represent significance between restoration groups for immediate and delayed; enamel and dentin. Small letters represent significance between immediate and delayed within enamel and dentin for each restoration.
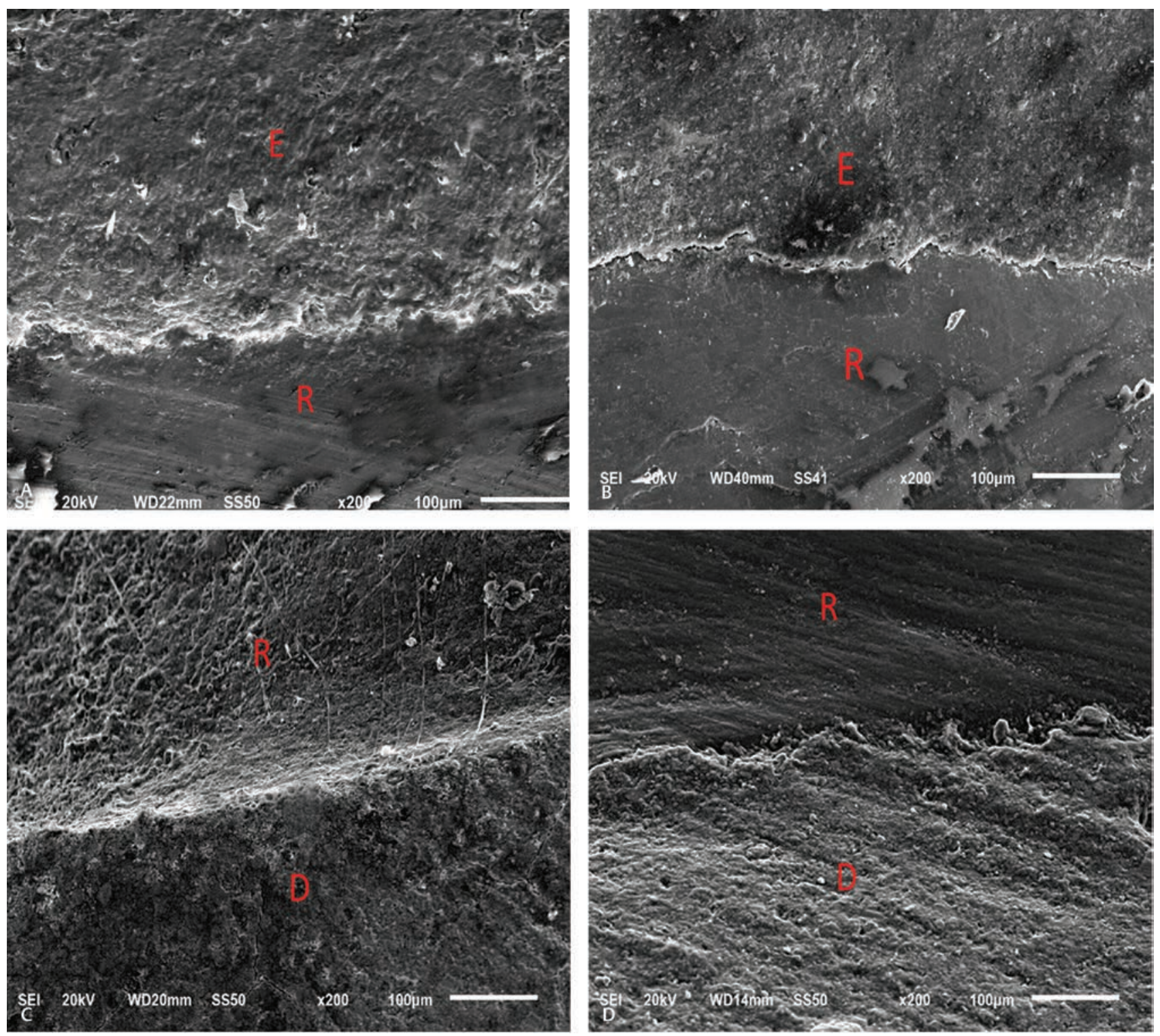

Fig. 1 Immediate evaluation of restorations: (A) continuous enamel margin, (B) noncontinuous enamel margin, (C) continuous dentin margin, (D) noncontinuous dentin margin. 

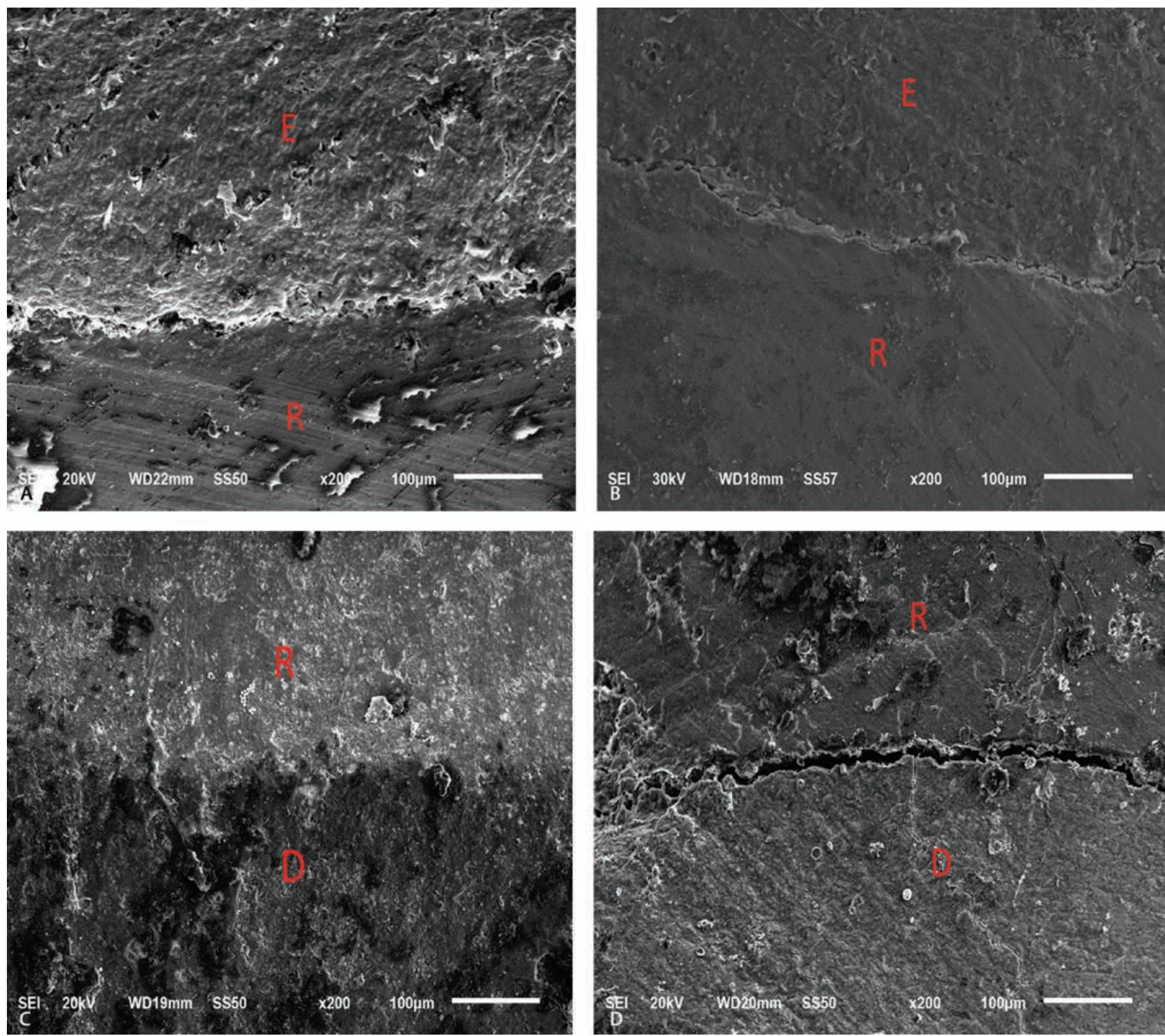

Fig. 2 Delayed evaluation of restorations: (A) continuous enamel margin, (B) noncontinuous enamel margin, (C) continuous dentin margin, (D) noncontinuous dentin margin.

Table 3 Comparison of microleakage among different types of restoration according to time and site

\begin{tabular}{|l|l|l|l|l|}
\hline \multicolumn{2}{|c|}{} & \multicolumn{3}{c|}{ Restoration } \\
\cline { 3 - 5 } \multicolumn{2}{c|}{} & GIC & RMGI & BIR \\
\hline \multirow{3}{*}{ Immediate } & Enamel & $0.00(0.00-0.00)^{\mathrm{Aa}}$ & $0.00(0.00-0.00)^{\mathrm{Aa}}$ & $0.00(0.00-0.00)^{\mathrm{Aa}}$ \\
\cline { 2 - 5 } & Dentin & $50(0.00-3.00)^{\mathrm{Aa}}$ & $0.50(0.00-1.00)^{\mathrm{Aa}}$ & $3.00(0.00-3.00)^{\mathrm{Aa}} \cdot$ \\
\hline \multirow{2}{*}{ Delayed } & Enamel & $0.50(0.00-1.00)^{\mathrm{Aa}}$ & $0.00(0.00-3.00)^{\mathrm{Aa}}$ & $0.00(0.00-0.00)^{\mathrm{Aa}}$ \\
\cline { 2 - 5 } & Dentin & $2.50(0.00-3.00)^{\mathrm{Aa}}$ & $2.50(1.00-3.00)^{\mathrm{Ab}}$ & $3.00(3.00-3.00)^{\mathrm{Aa}}$ \\
\hline
\end{tabular}

Abbreviations: BIR, bioactive ionic resin; GIC, glass ionomer cement; RMGI, resin-modified glass ionomer.

Note: Data expresses as median (IQR) IQR: interquartile range * : significance $<0.05$. Different letters represent significant difference. Capital letters represent significance between restoration groups for immediate and delayed; enamel and dentin. Small letters represent significance between immediate \& delayed within enamel and dentin of each restoration, ${ }^{*}$ : significance between enamel and dentin. 
should be a main objective for all clinicians. Microleakage is considered as a measure for the evaluation of restorations performance. Adherence of the material to the walls of the cavity is a criterion of ideal restorative material, as it prevents microleakage. This seepage can cause recurrent caries, pulpal injury, tooth discoloration, hypersensitivity of restored teeth, and accelerated deterioration of the restorative material. ${ }^{11}$

To ensure the clinical relevance of marginal adaptation and microleakage, materials should be used that are appropriate to clinical dentistry. Therefore, this study compared three widely used GI-based materials, one of them recently released to dental market named bioactive ionic resin (ACTIVA), which are the best choices for restoring class V. ${ }^{12}$

Every effort was made to standardize the methodology, and all steps were conducted by a single operator, and marginal adaptation was evaluated between different specimens using SEM. Direct scanning of dental structure was selected in this study because indirect epoxy resin replicas showed some disadvantages compared with direct examination. Resin replica fabrication is time consuming, also more liable to form excess of epoxy resin or voids. Furthermore, even when specimens can be replicated to preserve fidelity or to withstand the SEM vacuum conditions, it is difficult to determine the extent to which the structures of interest have been masked or altered by the preparation or replication process. ${ }^{13}$ Teeth were evaluated under SEM at a magnification of 200x. This magnification was selected relied on other studies that have evaluated marginal adaptation of various restorative materials, as it was important to differentiate between the different gaps criteria. ${ }^{14,15}$

Based on the results, the null hypothesis that marginal adaptation would not be affected by the type of restoration was accepted. In immediate results, there were no significant differences among the three restorative materials. Results of the present study are in agreement with the previous studies ${ }^{16,17}$ that strong chemical and micromechanical bonding to
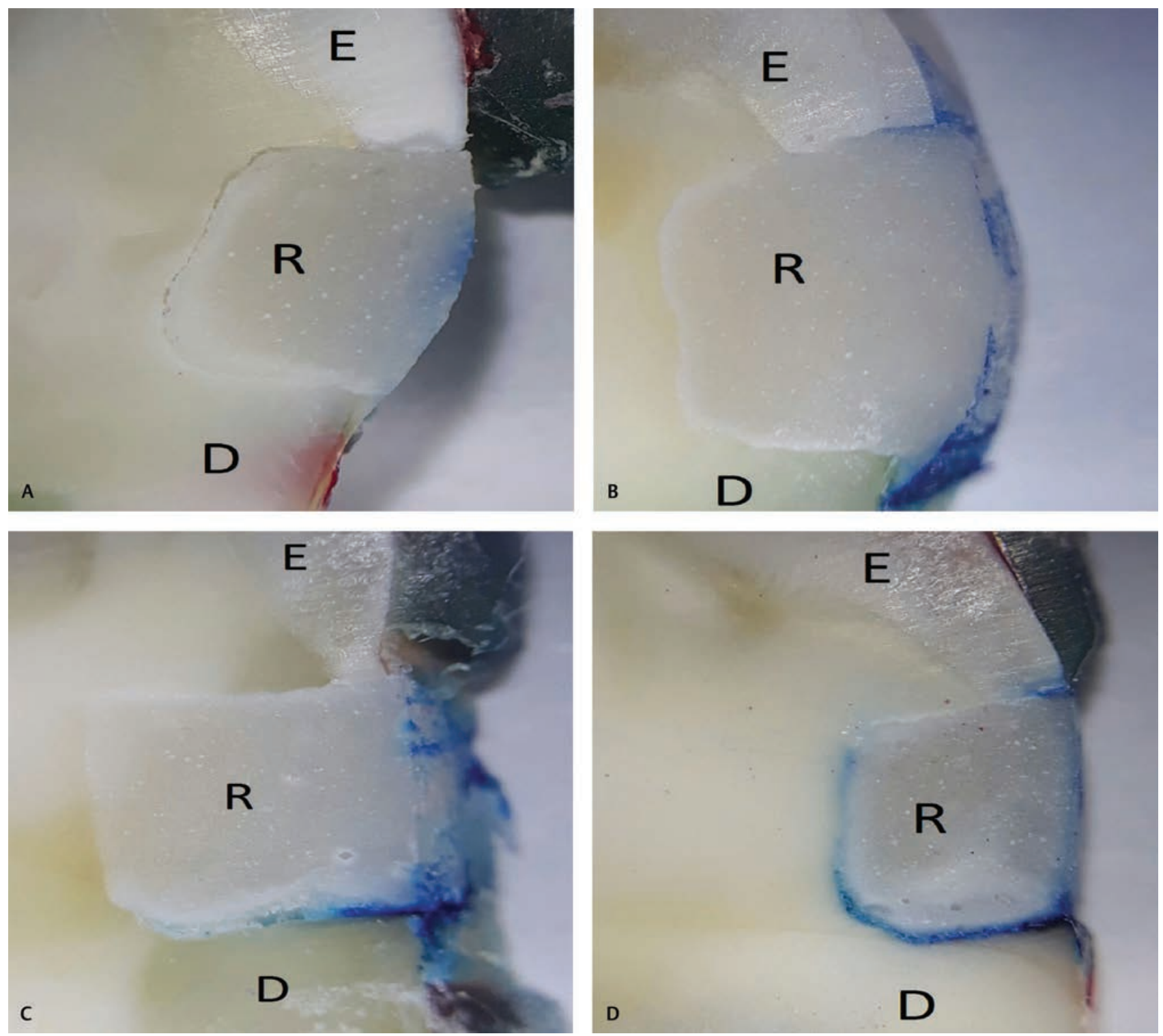

Fig. 3 Scoring of microleakage evaluation. (A) Score 0, (B) Score 1, (C) Score 2, (D) Score 3. E, enamel; D, dentin; R, restoration. 
the tooth structure and application of the coating material for GIC and RMGI have filled any gaps at the tooth restoration interface ${ }^{18}$ also increase the sealing properties of GIC as a result of the heat generated during its polymerization leading to increase in the molecular kinetic energy and rearrangement that may facilitate better adhesion. ${ }^{19,20}$ In addition, the flowability of the restorations allows better wetting along the cavity walls, thus +improving adaptation of dental restorations to the walls of the cavity. ${ }^{17}$

Moreover, there were no significant differences between enamel and dentin immediately, and these results were in acceptance with previous studies, ${ }^{21-23}$ which were based on enamel and dentin hybridization and how it improved the marginal seal of the restoration to tooth structure; in addition, the improvement in resin interaction to the tooth minerals forming a strong resin-hydroxy apatite complex so a positive marginal seal have occurred in enamel and dentin. However, the results obtaining in other studies ${ }^{24,25}$ showed that all dentin margins exhibited less marginal adaptation than enamel margins. This could be due to the differences in experimental designs and testing methods used in these studies.

In the delayed results, GIC and BIR showed some gaps ranging from 0 to $2 \mu \mathrm{m}$, while RMGI showed gaps that were larger than those in GIC and BIR ranging from 2 to $4 \mu \mathrm{m}$. However, these results were not significantly different from the immediate results, which may be due to abrasion of the coating material with time. Additionally, the coefficient of thermal expansion of RMGI and BIR differed from that of the tooth structure, and therefore, after thermocycling, there were slight changes in marginal adaptation.

On the other hand, the results of the previous studies were in contrast to this study, ${ }^{18,19}$ which may be explained by the tendency of RMGI to absorb water, leading to swelling and hydrolysis. One-week storage of RMGI in distilled water reduced the gap formation as a result of hygroscopic expansion.

Dye penetration test on sections of restored teeth is the most commonly used technique as it is a simple, fast, inexpensive technique that allows rapid and reliable results to be obtained without using complex laboratory equipment. ${ }^{20}$ Several dye penetration studies have been performed using $2 \%$ methylene blue dye to detect leakage because of its ease of manipulation, low cost, convenience, and low-molecular weight dye. ${ }^{26}$

Based on the results, the null hypothesis that the microleakage would not be affected by the type of restoration was partially accepted, as the microleakage affected by the site of the restoration and the dentin margin revealed more microleakage than enamel substrate, especially in BIR restorative material. Several studies have investigated that dentin bonding is less predictable as a result of its nonhomogeneous structure, lower inorganic content, and movement of fluids toward the external surface of dentin. $^{22}$ Furthermore, polymerization shrinkage and the coefficient of thermal expansion differences that occurred as a result of increasing resin content to $44.6 \%$ in the BIR structure.

After artificial aging, all the tested groups of restorations showed increased microleakage. The variations among the three materials were not significant, except for RMGI. There was a significant increase in microleakage between the immediate and delayed results. The RMGI values may be explained by the coefficient of thermal expansion..$^{24} \mathrm{RMGI}$ had a coefficient of thermal expansion $25.4 \times 10^{\circ} \mathrm{C}$ that was quite high compared with the tooth structure; as the thermocycling temperature decreases, a negative interfacial pressure is generated, which in turn encourages the ingress of oral fluids into the margins. Conversely, as the temperature increases, the interfacial temperature also increases. Consequently, the fluids are forced back to the surface; this phenomenon results in an increased degree of microleakage. ${ }^{25,26}$ As the coefficient of thermal expansion differences between tooth structure and restorative material increased, the potential for microleakage occurring also increased. ${ }^{27} \mathrm{GIC}$ had coefficient of thermal expansion $12.7 \times 10^{\circ} \mathrm{C}$ that near to that of the tooth structure (enamel is $\sim 11.4 \times 10^{\circ} \mathrm{C}$ and dentin $\sim 8.0 \times 10^{\circ} \mathrm{C}$ ). Moreover, BIR exhibited active emission of calcium, phosphate, and fluoride ions that benefit the longevity of the restoration and thus, there was no significant difference among their delayed and immediate results. ${ }^{28}$

The outcomes of this study were harmonious with previous studies ${ }^{29,30}$ these studies showed that RMGI has maximum leakage in comparison with GIC. However, results were in contrast to other studies, ${ }^{19,22}$ who concluded that RMGI has minimal leakage than GIC due to superior adhesion of RMGI with time and that differences may be due to the difference in the type of the GIC used in the study. However, further studies needed to be done to show the effect of thermocycling and aging on BIR.

\section{Conclusions}

1. The following conclusions can be drawn from this study: All the tested glass ionomer-based restorations reveal the same marginal adaptation and microleakage.

2. Microleakage could be affected negatively by water storage and this prominent with resin-modified glass ionomer.

3. Dentin margin reveals greater microleakage compared with enamel especially with bioactive ionic resin restorative material.

\section{Funding}

None.

\section{Conflict of Interest}

None declared.

\section{Acknowledgments}

The authors would like to express their thanks to Dr. Hamdi Hosney Hamama, Lecturer of Operative Dentistry, Operative Dentistry Department, Faculty of Dentistry, 
Mansoura University, for his valuable assistance in revising this manuscript.

\section{References}

1 Mount GJ, Tyas MJ, Ferracane JL, et al. A revised classification for direct tooth-colored restorative materials. Quintessence Int 2009;40(8):691-697

2 Mousavinasab SM, Meyers I. Fluoride release by glass ionomer cements, compomer and giomer. Dent Res J (Isfahan) 2009;6(2):75-81

3 Khoroushi M, Keshani F. A review of glass-ionomers: from conventional glass-ionomer to bioactive glass-ionomer. Dent Res J (Isfahan) 2013;10(4):411-420

4 McCabe JF, Yan Z, Al Naimi OT, Mahmoud G, Rolland SL. Smart materials in dentistry. Aust Dent J 2011;56(1, Suppl 1):3-10

5 Alrahlah A. Diametral tensile strength, flexural strength, and surface microhardness of bioactive bulk fill restorative. J Contemp Dent Pract 2018;19(1):13-19

6 Jyothi K, Annapurna S, Kumar AS, Venugopal P, Jayashankara C. Clinical evaluation of giomer- and resin-modified glass ionomer cement in class $\mathrm{V}$ noncarious cervical lesions: an in vivo study. J Conserv Dent 2011;14(4):409-413

7 De Caluwé T, Vercruysse CW, Ladik I, et al. Addition of bioactive glass to glass ionomer cements: effect on the physicochemical properties and biocompatibility. Dent Mater 2017;33(4):e186-e203

8 Aggarwal V, Logani A, Jain V, Shah N. Effect of cyclic loading on marginal adaptation and bond strength in direct vs. indirect class II MO composite restorations. Oper Dent 2008;33(5):587-592

9 Diwanji A, Dhar V, Arora R, Madhusudan A, Rathore AS. Comparative evaluation of microleakage of three restorative glass ionomer cements: an in vitro study. J Nat Sci Biol Med 2014;5(2):373-377

10 Abd Al Hbdan A. Review of microleakage evaluation tools. J Int Oral Health 2017;9(4):141-145

11 Kimyai S, Pournaghi-Azar F, Daneshpooy M, Abed Kahnamoii M, Davoodi F. Effect of two prophylaxis methods on marginal gap of $\mathrm{Cl}$ Vresin-modified glass-ionomer restorations. J Dent Res Dent Clin Dent Prospects 2016;10(1):23-29

12 Manhart J, Trumm C. Marginal adaptation of an etch-and-rinse adhesive with a new type of solvent in class II cavities after artificial aging. Clin Oral Investig 2010;14(6):699-705

13 Soares CJ, Celiberto L, Dechichi P, Fonseca RB, Martins LR. Marginal integrity and microleakage of direct and indirect composite inlays: SEM and stereomicroscopic evaluation. Braz Oral Res 2005;19(4):295-301

14 Bansal D, Mahajan M. Comparative evaluation of different periods of enamel microabrasion on the microleakage of class $\mathrm{V}$ resin-modified glass ionomer and compomer restorations: an in vitro study. Indian J Dent Res 2017;28(6):675-680

15 Magni E, Zhang L, Hickel R, Bossù M, Polimeni A, Ferrari M. SEM and microleakage evaluation of the marginal integrity of two types of class $\mathrm{V}$ restorations with or without the use of a light-curable coating material and of polishing. J Dent 2008;36(11):885-891
16 Gladys S, Van Meerbeek B, Lambrechts P, Vanherle G. Marginal adaptation and retention of a glass-ionomer, resin-modified glass-ionomers and a polyacid-modified resin composite in cervical Class-V lesions. Dent Mater 1998;14(4):294-306

17 Aggarwal V, Singla M, Miglani S. Effect of thermal and mechanical loading on marginal adaptation and microtensile bond strength of a self-etching adhesive with caries-affected dentin. J Conserv Dent 2011;14(1):52-56

18 Gjorgievska E, Nicholson JW, Iljovska S, Slipper IJ. Marginal adaptation and performance of bioactive dental restorative materials in deciduous and young permanent teeth. J Appl Oral Sci 2008;16(1):1-6

19 Sampaio PC, de Almeida Júnior AA, Francisconi LF, et al. Effect of conventional and resin-modified glass-ionomer liner on dentin adhesive interface of Class I cavity walls after thermocycling. Oper Dent 2011;36(4):403-412

20 Mali P, Deshpande S, Singh A. Microleakage of restorative materials: an in vitro study. J Indian Soc Pedod Prev Dent 2006;24(1):15-18

21 Amaral I, Gameiro A, Lopes L, Ventura I. In vitro study of microleakage and microhardness of high viscosity glass ionomer cement and resin modified glass ionomer cement. J Dent Oral Hyg 2017;1:283-289

22 Rekha CV, Varma B, Jayanthi. Comparative evaluation of tensile bond strength and microleakage of conventional glass ionomer cement, resin modified glass ionomer cement and compomer: an in vitro study. Contemp Clin Dent 2012;3(3):282-287

23 Owens BM, Phebus JG, Johnson WW. Evaluation of the marginal integrity of a bioactive restorative material. Gen Dent 2018;66(3):32-36

24 Pontes DG, Guedes-Neto MV, Cabral MF, Cohen-Carneiro F. Microleakage evaluation of class $\mathrm{V}$ restorations with conventional and resin-modified glass ionomer cements. Oral Health Dent Manag 2014;13(3):642-646

25 Omidi BR, Naeini FF, Dehghan H, Tamiz P, Savadroodbari MM, Jabbarian R. Microleakage of an enhanced resin-modified glass ionomer restorative material in primary molars. J Dent (Tehran) 2018;15(4):205-213

26 Fabianelli A, Sgarra A, Goracci C, Cantoro A, Pollington S, Ferrari $\mathrm{M}$. Microleakage in class II restorations: open vs closed centripetal build-up technique. Oper Dent 2010;35(3):308-313

27 Pinto-Sinai G, Brewster J, Roberts H. Linear coefficient of thermal expansion evaluation of glass ionomer and resin-modified glass ionomer restorative materials. Oper Dent 2018;43(5):E266-E272

28 Sadeghi M, Lynch CD. The effect of flowable materials on the microleakage of Class II composite restorations that extend apical to the cemento-enamel junction. Oper Dent 2009;34(3):306-311

29 Majety KK, Pujar M. In vitro evaluation of microleakage of class II packable composite resin restorations using flowable composite and resin modified glass ionomers as intermediate layers. J Conserv Dent 2011;14(4):414-417

30 Masih S, Thomas AM, Koshy G, Joshi JL. Comparative evaluation of the microleakage of two modified glass ionomer cements on primary molars. An in vivo study. J Indian Soc Pedod Prev Dent 2011;29(2):135-139 